DOI: $10.2478 / \mathrm{v} 10282-012-0003-4$

\title{
Intra et parasellar chordoma
}

\author{
G. Iacob ${ }^{1}$, M. Crăciun ${ }^{1}$, Liliana Parascan ${ }^{2}$, Maria Sajin $^{3}$ \\ ${ }^{1}$ Neurosurgery Clinic, Universitary Hospital, Bucharest \\ ${ }^{2}$ Department of Pathology \\ Cardiovasculary Hospital, Prof. Dr. C.C. Iliescu, Bucharest \\ ${ }^{3}$ Department of Pathology, Universitary Hospital, Bucharest
}

\begin{abstract}
A rare case of giant intra and parasellar chordoma, mimicking a pituitary prolactinoma is presented. The tumor involving pituitary fossa and surrounding structures was removed via a bifrontal approach. The pathology exhibited the typical histological patterns of a chordoma. The authors present a rare case of a giant sellar and parasellar chordoma and review the literature on that.
\end{abstract}

Keywords: chordoma, sella turcica, pituitary prolactinoma

\section{Introduction}

Chordomas represent $1 \%$ of all malignant bone tumors and 0.1 to $0.2 \%$ of intracranial neoplasms $(6,7)$. In Romania, the Pathology Department of the Bucharest Oncologic Institute has reported a low frequency for chordoma $0.12 \%$. These embrionary tumors, first described by Luschka in 1856 are rare, slow-growing neoplasms with maligne potential, that arise from cell rests, particularly of the proximal and distal extremes of the notochord, characterized by osseous permeation, high local recurrence, local invasiveness (4-14). Their metastatic potential cannot be estimated by histological examination, except in cases of sarcomatous transformation (10). The most common site are: $50 \%$ in the sacrococcygeal region mean age 50 years, especially to men, 35\% in the base of skull - in the midline, especially to childs or young adults; $15 \%$ in vertebrae (7). Large, intra et parasellar chordomas resembling a pituitary prolactinoma are rare (12).

\section{Case presentation}

A 64 year old woman, without pathological antecedents, was admitted in our department for headache, progressive decrease of visual acuity of right eye, double vision instaled over the past 2 months. On general and neurological examination we found decrease of visual acuity of right eye: $\operatorname{VOD}=2 / 3$ without corection, $\operatorname{VOS}=1$, the external rotation of the right eyeball was not possible, visual field examination disclosed bitemporal hemianopsia; fundus oculi: plane, well contured papila, with tortous and dilated veins, thin arteries, macula without reflex on right eye; the light reflex of both pupils in direct \& indirect responses was normal. No endocrinopathy was noted but serum pituitary hormone levels revelead high prolactin levels: 84 $\mathrm{ng} / \mathrm{ml}$, reference value $2.5-17$, less basal cortisolemia $1,24 \mu \mathrm{g} / \mathrm{dl}$, reference value 525, betachorionic gonadotropin (hCG), alpha-fetoprotein (FP) and carcinoembryonic antigen (CEA) were 
normal; diabetes insipidus investigation also was normal.

Radiography of the skull revealed enlargement and distortion of the sella, with osteolysis of its floor and invasion of the sphenoid bone. A high-resolution CT scan revealed a large, partly calcified intrasellar tumor, showing suprasellar extension and erosion of the sphenoid bone.

Cerebral MRI (Figure 1) demonstrated a sellar area tumor measured 28/32/34 mm, in its greatest diameter, with hypersignal in T1 and T2-weighted images, omogenous, with slight inside calcifications, polycyclic outlined. This tumor is elevating the pituitary gland and optic chiasm, posterior overpass clivus, is in contact with the basilary artery and on the right side invaded the latero-selar compartment, without affecting the carotid artery. Therefore the carotid arteriography was normal.

A bifrontal microscopic approach was performed; a yellow encapsulated, soft with necrotic center tumor was discovered, extended intra, supra and right parasellar. The tumor was removed, the latero-selar compartment too, the optic chiasm was decompressed as like as the pituitary stalk, less a small part of the tumor with tight adhesion to the pituitary stalk. Microcalcifications in the suprasellar and sellar portions were detected. Postoperatory evolution was uneventfull confirmed by cerebral CT (Figure 2) and at 6-months follow-up examination after radiotherapy, the patient was asymptomatic, serum pituitary hormone levels revelead normal levels.

Histologic and immunohistochemistry tests are indicative for a tumoral chordoma. Patolology diagnosis was made on macroscopic criteria: lobulated fragments, tan-to-red, of various dimensions, soft consistency, sometimes kistic, diffuse borders, invading adiacent structures.
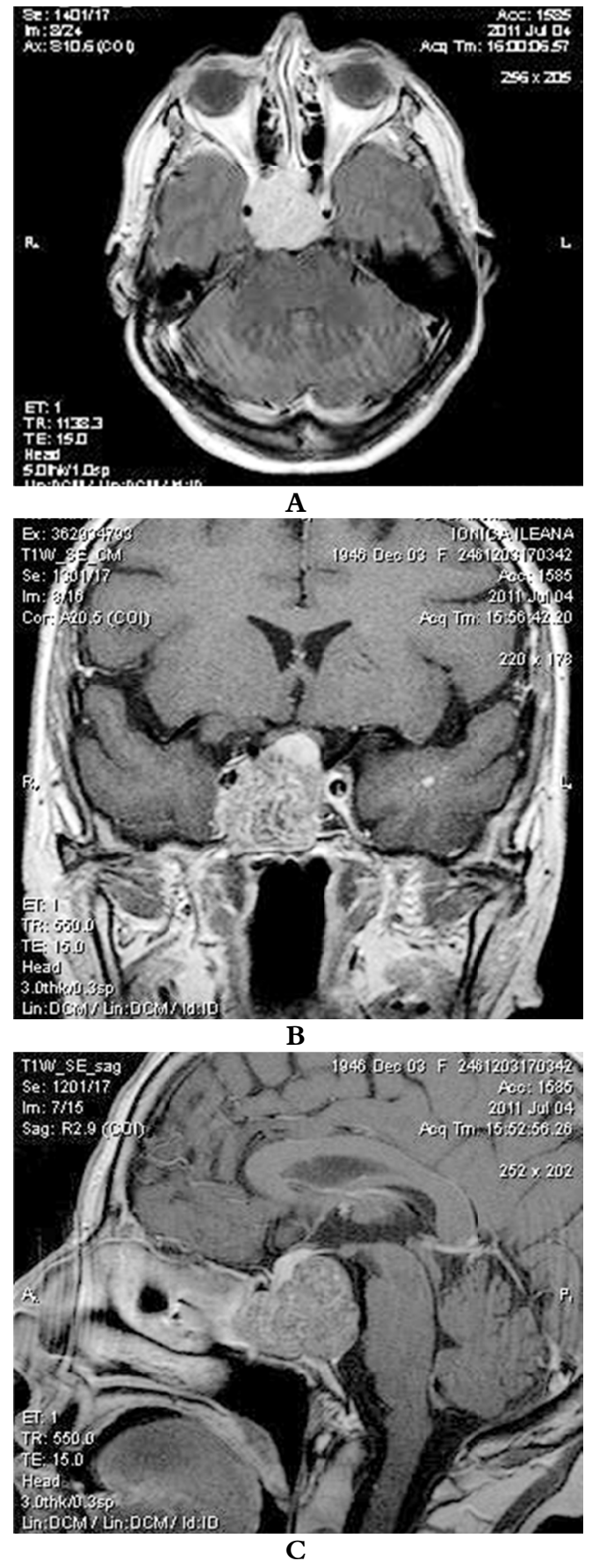

Figure 1 Cerebral MRI studies: axial (A), coronal (B) and sagittal (C) revealing a large mass occupying the pituitary fossa, elevating the pituitary gland and optic chiasm, and invading the right cavernous sinus 
DOI: 10.2478/v10282-012-0003-4

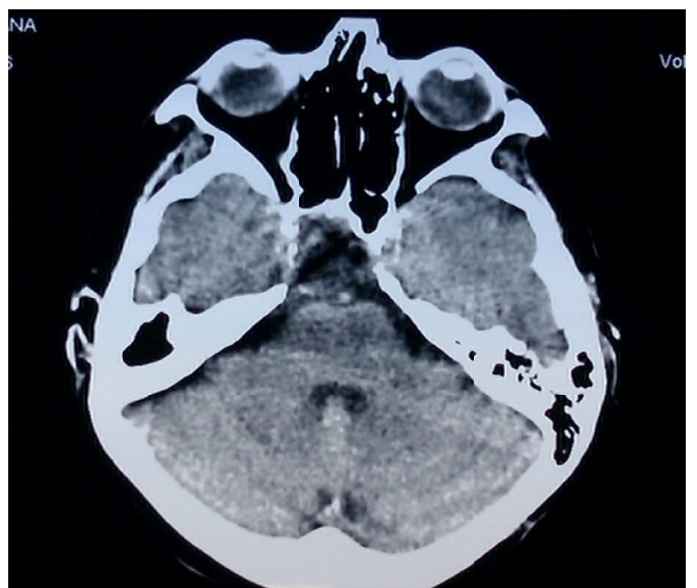

Figure 2 Postoperatory CT-scan 1 month after operation

On section tumor is gelatinous, translucide with green with red-brune areas. Microscopic criteria (Figure 3): lobular pattern, more important in central part of the tumor, with different shapes, fibrous septa of variable thickness, more important at the tumor periphery, containing vessels. The arterial supply in the central area were very small, but necrosis was very offen encountred. Smaller lobuli, perhaps younger, disposed at the peryphery, contain oval, polygonal or prismatic cells, mimiking a carcinomatous aspect. This cells has important cytoplasma, omogenous, with small vacuolar areas containing glicogen and progressive tendency to coalescence. The nuclei are small, spheric rarely with reniform shape, disposed central with prominent nucleoli. In the cells with multiple vacuolar areas, nuclei has the tendency to picnosis.

In medium or big lobuli the proliferative cells were disposed circumferential and extended to the centrum part of the lobuli with a radial structure. In the central area, intracytoplasmatic vacuoles develop in volume and number; by vacuoles coalescence cells has the tendency to become "physaliphorous cells" with small nuclei disposed central or in the periphery (physaliphorous comes from the greek word physalis = bubble). Gigant, multinucleated cells are rare. Cytoplasmic vacuoles were smaller than those in the intercellular matrix. Another microscopic criteria was represented by an important mucoid stroma with glycogenic component (see the period-acid-Schiff method), where cells arranged in lobules are embedded. Very rare cells has pseudo-glandular aspects with limphocytes at the periphery, partial limitated by a capsula made by conjunctive tissue.

Immunocytochemical analysis of the chordoma cells showed focal positivity for vimentin, EMA. Negative immunoreactivity for CEA was noted. Ultrastructurally, the tumor was composed of large cells containing irregular nuclei with multiple indentations and prominent nucleoli. Analysis of DNA revealed a diploid histogram.

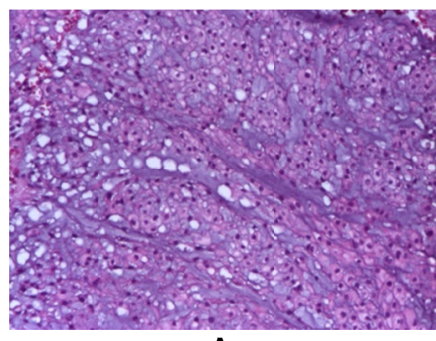

A

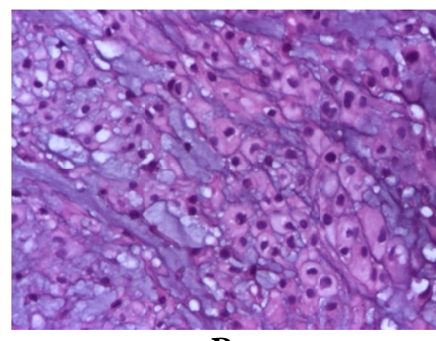

B

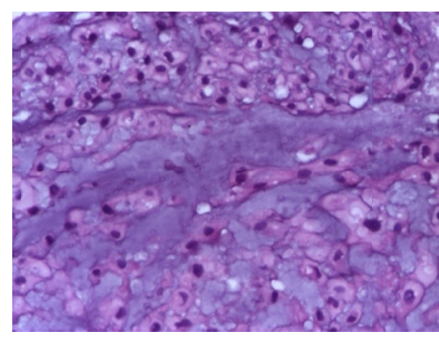

C 


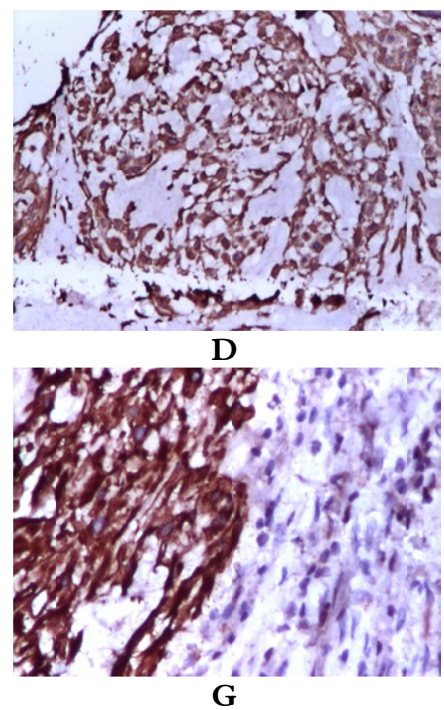

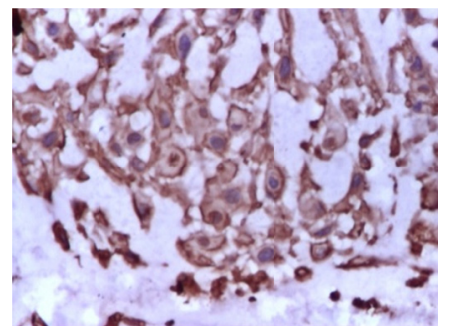

E

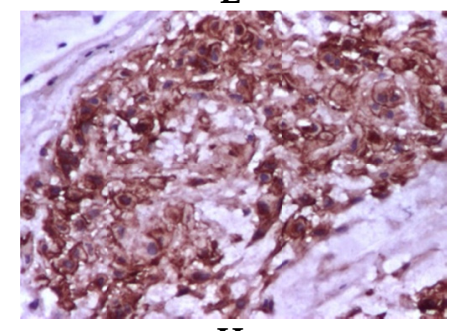

$\mathbf{H}$

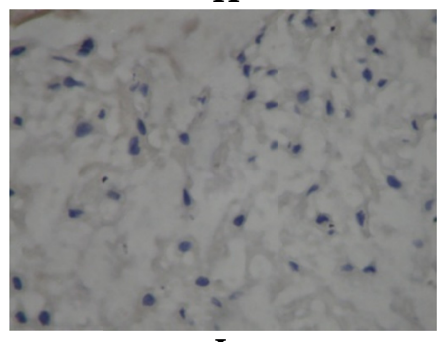

$\mathbf{J}$

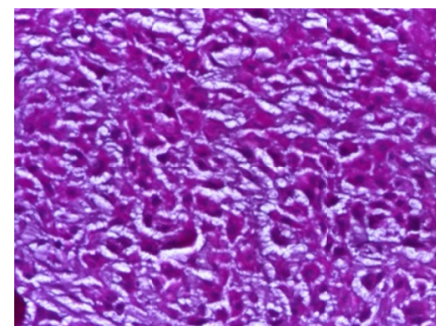

$\mathbf{F}$

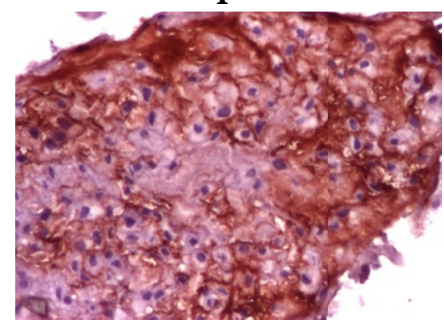

I

Figure 3 Chordoma: microscopic criteria and details for immunohistochemistry (A) chordoma HE - Ob.10 X: tumoral lobes, different shapes, sepparated by fibrotic septs,

(B) detail: chordoma HE - Ob. $20 \mathrm{X}$ : as vacuoles are bigger, the cells limit are estompated, (C) another detail of chordoma HE - Ob. $20 \mathrm{X}$, (D) VIM positive IHC coloration - Ob.10 X, (E) detail of VIM positive IHC coloration - Ob. $20 \mathrm{X}$, (F) PAS present as a marker of glicogen in mucilaginous substance expelled in extracells space - Ob. 20 X, (G) detail of MNF (myelinated nerve fibres) 116 positive diffuse - Ob. $20 \mathrm{X}$, (H) detail of EMA (epithelial membrane antigen) positive diffuse - Ob. $20 \mathrm{X}$, (I) LEU 7 - zonnal positive Ob. $20 \mathrm{X}$, (J) CEA (carcinoembryonic antigen) negative - Ob. $40 \mathrm{X}$

\section{Discussion}

Chordomas involving the sellar region are extremely rare, more frequent in younger patients - second to fifth decades of life, with a a male/female ratio of 6: 5 (5, 7) Most chordomas involving the sellar region depending on anatomical location and clinical features could be devided in three groups (12): parasellar or suprasellar chordomas with optic tract compression and oculomotor nerve palsy; largely or entirely sellar chordomas - are very rare, mimicking pituitary adenoma with chiasm compression and hypopituitarism, clival chordomas with brainstem compression and bilateral sixth cranial nerve paresis. Several studies according to Thoudou et al. (12) has pointed the misdiagnosed preoperatively as pytuitary adenoma, craniopharingioma based on clinical symptoms (visual deficit as the most common symptom, hyperprolactinemia or hypopituitarism more commonly observed in the sellar and suprasellar chordomas) and radiologic findings (bone distruction involving pituitary fossa, petrous bone, 
orbit, foramen ovale, jugular foramen and even foramen magnum; calcifications in the tumoral mass or sequestrated bone fragment) The skull base chordomas tend to present osseous permeation, and have a high rate of recurrence $(4-7,10,14,15)$. Their metastatic potential cannot be estimated by histological examination, except in cases of sarcomatous transformation $(1-3,6,8,10)$.

The imaging method of choice are MRI, also CT - scan with contrast and thin slices for reconstructions (7). A sellar chordoma CT scan may reveal a contrast-enhancing intrasellar mass with bony erosions and calcifications well demonstrated in bone window images $(11,15)$.

In general surgery should be complete, the capsular tumoral adhesions to chiasma or another nervous structure made this purpose sometimes impossible and postoperative irradiation are recommended despite inconclusive data $(7,10,12)$.

The immunohistologic profile of chordoma cells is reactivity to cytokeratins, vimentin, and epithelial membrane (1-3, 7, 9). The only known prognostic study published in 1993 estimated overall survival rates of $51 \%$ and $35 \%$ at 10 and 20 years, respectively (6). Differential diagnosis should be made with other large sellar and suprasellar tumor mass as pituitary adenomas, especially if a calcified intrasellar tumor with bone erosion is diagnosed; chondroid chordoma, chondrosarcoma with mucoid intercellular substance containing calcifications $(5,7,14)$.

\section{Conclusion}

Chordomas are midline slow-growing tumors that arise from proximal and distal extreme remnants of the notochord, are locally invasive, may metastasize and are characterized by local recurrence. These tumor can mimick a pituitary adenomas, especially if a calcified intrasellar tumor with bone erosion is diagnosed. A grosstotal resection followed by radiotherapy, has been the accepted treatment for sellar chordomas.

\section{References}

1. Abenoza P, Sibley RK, "Chordoma: an immunohistologic study," Human Pathology 1986, 17, 7, 744-747

2. Bouropoulou V, Kontogeorgos G et al, Differential diagnosis of chordoma immunohistochemical aspects, Archives d'Anatomie et de Cytologie Pathologiques 1987, 35, 1, 35-40

3. Coindre JM, Rivel J et al, Immunohistological study in chordomas, Journal of Pathology 1986, 150, 1, 61-63

4. Cremoux P, Turpin U, Hamon P, Gennes JL, "Les chordomes intrasellaires. Principaux aspects cliniques, biologiques, radiologiques, évolutifs et histologiques A propos de deux observations," Sem Hôp, 1980, 56, 1769-1773

5. Elias Z, Powers SK, "Intrasellar chordoma and hyperprolactinemia," Surgical Neurology, 1985, 23, 2, 173-176

6. Forsyth PA, Cascino TL, Shaw EG et al, Intracranial chordomas: a clinicopathological and prognostic study of 51 cases, Journal of Neurosurgery 1993, 78, 5, 741747

7. Hirosawa RM, Santos ABA, Franc MM et al, Intrasellar Chondroid Chordoma: A Case Report, ISRN Endocrinology 2011, ID 259392, 5, 259392

8. Mathews W, Wilson CB, "Ectopic intrasellar chordoma. Case report," Journal of Neurosurgery, 1974, 40, 2, 260-263

9. Pluot M, Bernard MH et al, Deux observations de chordome de la selle turcique. Etude ultrastructurale et histochimique, Archives d'anatomie et de cytologie pathologiques 1980, 28, 230-236

10. Raffel C, Wright DC, Gutin PH, Wilson CB, Cranial chordomas: clinical presentation and results of operative and radiation therapy in twenty-six patients, Neurosurgery 1985, 17, 5, 703-710

11. Tan WS, Spigos D, Khine N, Chordoma of the sellar region, Journal of Computer Assisted Tomography 1982, 6, 1, 154-158

12. Thodou E, Kontogeorgos $\mathrm{G}$ et al, Intrasellar chordomas mimicking pituitary adenoma, Journal of Neurosurgery 2000, 92, 6, 976-982

13. Volpe R, Mazabraud A, A clinicopathologic review of 25 cases of chordoma, A pleomorphic and metastasizing neoplasm, American Journal of Surgical Pathology 1983, 7, 2, 161-170

14. Watkins LN, Khudados ES et al, Skull base chordomas: a review of 38 patients, 1958-88, British Journal of Neurosurgery 1993, 7, 3, 241-248

15. Zee CS, Go JL et al, Imaging of the pituitary and parasellar region, Neurosurgery Clinics of North America 2003, 14, 1, 55-80. 